\title{
Clinicopathological Significance of Vascular Endothelial Growth Factor-C in Breast Carcinoma with Long-Term Follow-Up
}

Yasushi Nakamura, M.D., Ph.D., Hironao Yasuoka, M.D., Masahiko Tsujimoto, M.D., Ph.D., Qifeng Yang, M.D., Ph.D., Ayumi Tsukiyama, CT., Shigeru Imabun, M.D., Masaaki Nakahara, M.D., Kazuyasu Nakao, M.D., Misa Nakamura, Ph.D., Ichiro Mori, M.D., Ph.D., Kennichi Kakudo, M.D., Ph.D. Second Department of Pathology, Wakayama Medical University, Wakayama City (YN, HY, QY, MN, IM, KK); Department of Pathology, Osaka Police Hospital, Osaka (MT, AT); and Department of Surgery, Osaka Police Hospital, Osaka (SI, MN, KN), Japan

Expression of angiogenic and lymphangiogenic factors by tumors may influence the route of metastatic spread. The angiogenic factor vascular growth factor-C (VEGF-C) is implicated in the development of lymphatic vessels and promotion of lymphatic metastasis. The purpose of this study was to determine whether VEGF-C correlates with lymph node metastasis or prognosis. We assessed VEGF-C expression using immunohistochemistry in 123 invasive breast carcinomas with long-term follow-up. The relationship between VEGF-C expression and lymph node status and other established clinicopathological parameters was assessed. Whether VEGF-C expression plays a prognostic role in breast cancer was also investigated. VEGF-C expression was identified in 103 cases (83.7\%). Positive VEGF-C was significantly correlated with lymph node metastasis $(P=0.0131)$. Survival curves determined by the Kaplan-Meier method and univariate analysis demonstrated that positive VEGF-C was associated with both disease-free survival $(P=0.0165)$ and overall survival $(P=0.0175)$. On the basis of our findings, VEGF-C plays a crucial role in lymph node metastasis and may be a significant prognostic factor for long-term survival in breast cancer.

KEY WORDS: Breast cancer, Immunohistochemistry, Metastasis, Prognosis, VEGF-C.

Mod Pathol 2003;16(4):309-314

Copyright $\odot 2003$ by The United States and Canadian Academy of Pathology, Inc.

VOL. 16, NO. 4, P. 309, 2003 Printed in the U.S.A.

Date of acceptance: January 8, 2003.

Address reprint requests to: Yasushi Nakamura, M.D., Ph.D., Second

Department of Pathology, Wakayama Medical University, 811-1, Kimi-

idera, 641-8509 Wakayama City, Japan; fax: 8173 446 4825; e-mail:

ynakamur@mail.wakayama-med.ac.jp.

DOI: 10.1097/01.MP.0000062858.98295.9F
The vascular endothelial growth factor (VEGF) family is a group of growth factors that regulate the growth of endothelial cells $(1,2)$. The well-known member VEGF-A plays essential roles in vasculogenesis and angiogenesis (3), and its crucial role in tumor angiogenesis and blood-born metastasis has been documented in a variety of cancers (4). Recently, VEGF-C, a novel VEGF member, has been found to induce not only angiogenesis but also lymphangiogenesis via VEGF receptor-2 (VEGF-R2) and VEGF receptor-3 (VEGF-R3; 5, 6). Because VEGF-R3 has been demonstrated to be expressed almost exclusively in the lymphatic endothelium and thus considered to be a major regulator of lymphangiogenesis $(7,8)$, VEGF-C appears to be an important lymphangiogenic factor. The correlation of VEGF-C expression with lymph node metastasis has been reported in many malignant tumors (9-19).

In breast carcinoma, tumor involvement of the axillary lymph nodes is considered to be the most important prognostic factor (20). VEGF-C was strongly correlated with lymph node metastasis in animal model (21); however, the relationship between VEGF-C expression and lymph node metastasis has not been established in clinical trials (22-24).

In this study, we analyzed the relationship between expression of VEGF-C and clinicopathological features in breast cancer with a long-term follow-up. Our studies showed that the expression of VEGF-C was strongly correlated with lymph node metastasis and patients' prognosis.

\section{MATERIALS AND METHODS}

\section{Patients and Tumor Samples}

The study included 123 women with invasive breast cancer that was diagnosed and treated in the 
Osaka Police Hospital, Osaka, Japan between 1981 and 1992. The age ranged from 24 to 87 years (mean 51 years). The median follow-up period of the patients was 109 months (range, 5.5 to 230 months). All women were apparently free of distant metastasis and underwent curative surgery. Patient and tumor characteristics are shown in Table 1. The pathologic classification of each sample was confirmed by a review of hematoxylin and eosinstained sections.

\section{Immunohistochemistry}

The primary antibody used in study was an antiVEGF-C goat polyclonal antibody (R \& D Systems, Inc, Minneapolis, MN). Paraffin sections that were 4 $\mu \mathrm{m}$ thick were deparaffinized and autoclaved for antigen retrieval. Then they were placed in a solution of absolute methanol and 3\% hydrogen peroxidase for 5 minutes. They were subsequently washed in phosphate-buffered saline (PBS) and treated for 20 minutes with Protein Block Serumfree (DAKO Co, Carpinteria, CA). The sections were treated with anti-VEGF-C antibody diluted 1:400 in PBS and then were incubated at $4^{\circ} \mathrm{C}$ in a humidified chamber. After the overnight treatment, the slides were incubated with Histofine Simple Stain MAX PO (G; NICHIREI, Tokyo, Japan) for 60 minutes according to the manufacturer's instructions. The color was developed using diaminobenzidine with $0.01 \%$ hydrogen peroxidase. Counterstaining

TABLE 1. The Relationship between VEGF-C Expression and Other Parameters

\begin{tabular}{|c|c|c|c|}
\hline \multirow{2}{*}{ Factor } & \multicolumn{2}{|c|}{ VEGF-C } & \multirow{2}{*}{$P$ Value } \\
\hline & Negative & Positive & \\
\hline Age & & & 0.2189 \\
\hline$<50$ & 14 & 54 & \\
\hline$\geq 51$ & 6 & 49 & \\
\hline Histology & & & 0.0006 \\
\hline IDC & 14 & 100 & \\
\hline Others & 6 & 3 & \\
\hline Tumor size & & & 0.1157 \\
\hline$\leq 2 \mathrm{~cm}$ & 10 & 29 & \\
\hline$>2 \mathrm{~cm}$ & 10 & 69 & \\
\hline Lymph node metastasis & & & 0.0131 \\
\hline Negative & 15 & 44 & \\
\hline Positive & 5 & 59 & \\
\hline ER & & & 0.1445 \\
\hline Negative & 5 & 44 & \\
\hline Positive & 15 & 58 & \\
\hline PgR & & & 0.1474 \\
\hline Negative & 6 & 49 & \\
\hline Positive & 14 & 52 & \\
\hline c-erbB-2 & & & 0.0575 \\
\hline Negative & 18 & 69 & \\
\hline Positive & 2 & 34 & \\
\hline p53 & & & 0.4430 \\
\hline Negative & 15 & 64 & \\
\hline Positive & 5 & 38 & \\
\hline Grade & & & 0.4643 \\
\hline I and II & 13 & 56 & \\
\hline III & 7 & 47 & \\
\hline
\end{tabular}

was done with hematoxylin. For the negative control, all reagents except for the primary antibody were used. Evaluation of VEGF-D immunoreactivity was carried out independently by two investigators who did not have clinical or laboratory knowledge of the patients. The immunostained sections were scanned by light microscopy, and all of the tumor cells were evaluated. Only cases in which $\geq 10 \%$ of tumor cells were immunoreactive were scored as positive according to Kinoshita et al. (22).

\section{Covariates}

Information about the patients' clinical history was obtained from the patients' medical records. The immunostaining results of estrogen receptor (ER), progesterone receptor (PgR), p53, and c-erbB-2 were obtained from our pathological data files. The size of the primary tumor was considered to be the largest tumor diameter observed after surgical excision. Lymph node status was determined by counting the number of axillary lymph nodes with histological evidence of metastatic breast carcinoma. Histological typing and nuclear grading were performed as described elsewhere (25, 26), respectively.

\section{Statistics}

Fisher's exact test was used to examine the association between different variables and clinicopathological factors. DFS (disease-free survival) curves and OS (overall survival) curves were obtained using the Kaplan-Meier method and compared using the log-rank test. A multivariate model using the Cox stepwise regression analysis was used to evaluate the statistical strength of independent association between covariates and DFS and/or OS. A $P$ value of $<.05$ was considered significant. A computer program package (StatView 5.0, Abacus Concepts, Berkeley, CA) was used for all statistical testing and management of the database.

\section{RESULTS}

\section{VEGF-C Expression in Breast Cancer Tissue}

In breast cancer cells, expression of VEGF-C protein was observed in the cytoplasm. The VEGF-C staining is heterogenic. In some cases, almost all invasive cells were immunopositive for VEGF-C (Fig. 1A), whereas in others, the invasive cells were negative (Fig. 1B). According to the criteria for VEGF-C immunostaining evaluation, VEGF-C protein was positive in $83.7 \%(103 / 123)$ of the breast cancer patients. In addition, VEGF-C expression was often more intense in the invasive edge and/or intraductal component (Fig 1C). In contrast, very little or no staining was observed in normal mam- 

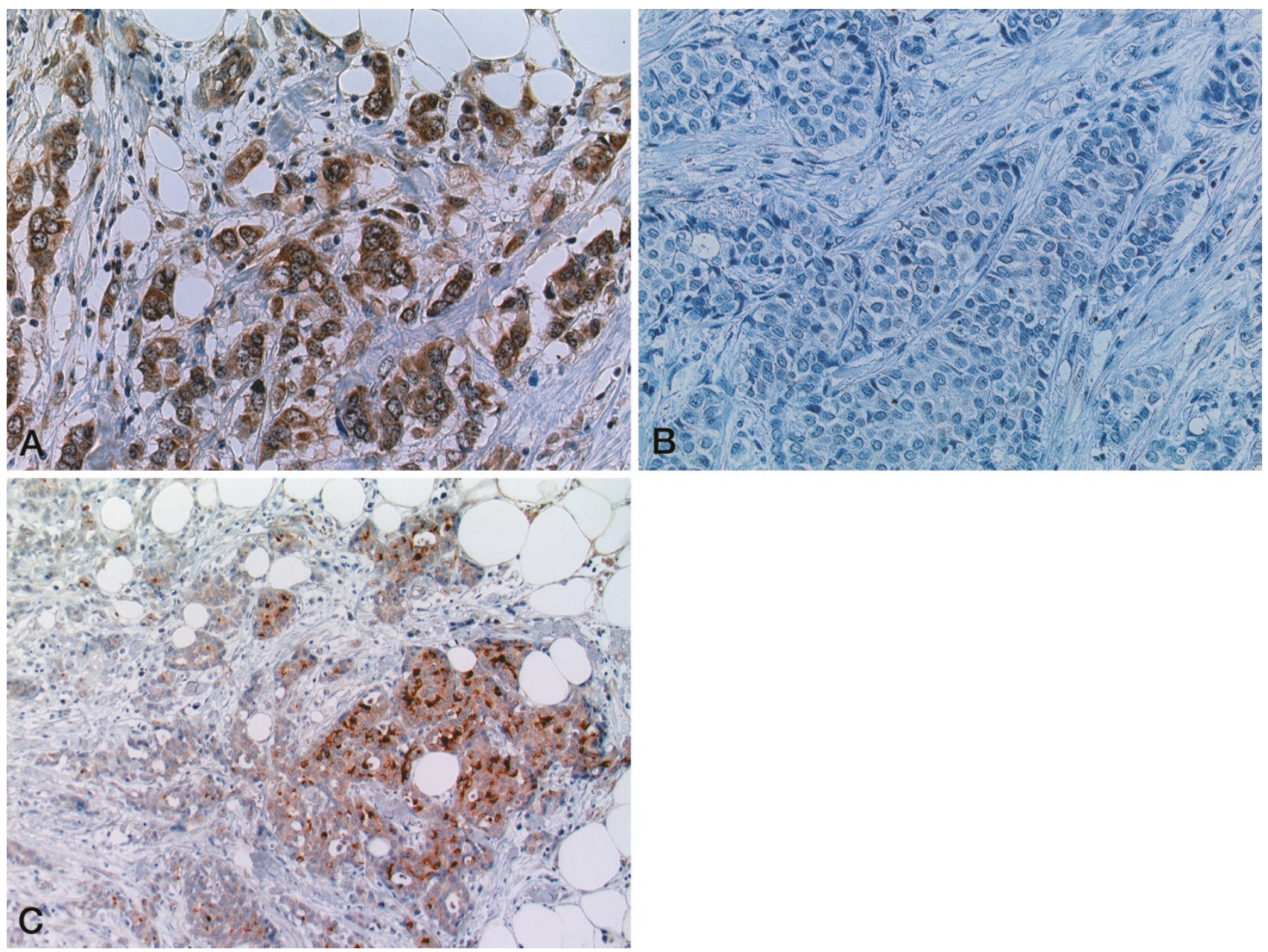

FIGURE 1. Vascular endothelial growth factor-C (VEGF-C) expression patterns in invasive breast carcinomas. A, almost all tumor cells show diffuse and intense immunostaining. B, the tumor cells are completely unreactive. C, VEGF-C expression was often more intense in the invasive edge.

mary cells surrounding the affected ducts, although a weak signal was seen in unaffected normal ductal epithelium occasionally.

\section{Correlations between VEGF-C Expression and Clinicopathological Factors}

The correlation between VEGF-C expression and clinicopathological factors was summarized in Table 1. VEGF-C expression was more frequently found in tumors with lymph node metastasis than in those without it $(P=.0131)$. There was no significant correlation between VEGF-C expression and the age of the patients, tumor size, hormone receptor status, c-erbB-2 status, p53 status, or nuclear grading.

\section{VEGF-C and Patients' Survival}

The survival analysis was performed on all the patients and took into account the following variables: VEGF-C, patient's age, histological type, tumor size, lymph node status, hormonal status, c-erbB-2 status, p53 status, and nuclear grade. Uni- variate survival analysis showed that tumor size, lymph node status, ER, and VEGF-C were of significant prognostic value for DFS (Table 2; Fig. 2A); tumor size, lymph node status, PgR, and VEGF-C were of significant prognostic value for OS (Table 3; Fig. 2B). Based on multivariate cox regression analysis, only lymph node status was identified as an independent prognostic factor (DFS, $P=.004$; OS, $P=.0079)$. We failed to identify VEGF-C expression as an independent prognostic factor for DFS and OS (data not shown).

\section{DISCUSSION}

In the present study, we found that VEGF-C was up-regulated in invasive breast cancer. VEGF-C expression was often more intense in the invasive edge, where release of angiogenic factors would be anticipated (27) and/or peritumoral lymphangiogenesis would be induced (28).

A previous report showed that VEGF-C mRNA expression in estrogen-dependent breast cancer cell line MCF-7 (28) is down-regulated by estrogen 
TABLE 2. Univariate Analysis of Disease-Free Survival (DFS) by Various Clinicopathological Factors Factor

\begin{tabular}{|c|c|c|c|}
\hline \multirow{2}{*}{ Factor } & \multirow{2}{*}{ Number } & \multicolumn{2}{|l|}{ DFS } \\
\hline & & Number of Recurrences (\%) & $\mathrm{P}$ Value \\
\hline Age & & & 0.3559 \\
\hline$<50$ & 66 & $21(31.8)$ & \\
\hline$\geq 51$ & 52 & $20(38.4)$ & \\
\hline Histology & & & 0.4879 \\
\hline IDC & 109 & $39(35.7)$ & \\
\hline Others & 9 & $2(32.2)$ & \\
\hline Tumor size & & & 0.0048 \\
\hline$\leq 2 \mathrm{~cm}$ & 39 & $6(15.3)$ & \\
\hline$>2 \mathrm{~cm}$ & 76 & $33(43.4)$ & \\
\hline Lymph node metastasis & & & $<0.0001$ \\
\hline Negative & 59 & $9(15.2)$ & \\
\hline Positive & 59 & $32(54.2)$ & \\
\hline $\mathrm{ER}$ & & & 0.0354 \\
\hline Negative & 48 & $21(43.7)$ & \\
\hline Positive & 69 & $19(27.5)$ & \\
\hline PgR & & & 0.2210 \\
\hline Negative & 53 & $20(37.7)$ & \\
\hline Positive & 63 & $19(30.1)$ & \\
\hline c-erbB-2 & & & 0.2981 \\
\hline Negative & 83 & $27(32.5)$ & \\
\hline Positive & 35 & $14(40.0)$ & \\
\hline p53 & & & 0.7600 \\
\hline Negative & 74 & $27(36.4)$ & \\
\hline Positive & 43 & $13(30.2)$ & \\
\hline Grade & & & 0.7587 \\
\hline I and II & 66 & $23(34.8)$ & \\
\hline III & 52 & $18(34.6)$ & \\
\hline VEGF-C & & & 0.0165 \\
\hline Negative & 20 & $2(10.0)$ & \\
\hline Positive & 98 & $39(39.7)$ & \\
\hline
\end{tabular}

(29). However, we could not find any relationship between VEGF-C expression and ER status in our present study.

Lymph node metastasis is the oldest and most reliable prognostic indicator in breast carcinoma. A recent hypothesis is that most breast carcinomas are systemic from the onset, but the axillary lymph node status still has major prognostic implications (30-33). Therefore, it is understandable that in evaluation of the clinical stage of breast carcinoma and, consequently, therapy and outcome, emphasis continues to be placed on axillary lymph node status. Our findings showed that VEGF-C expression was associated with lymph node metastasis in breast cancer. Our results are consistent with a recent report in a Balb-cA Bom-nu mice model that VEGF-C-induced lymphangiogenesis is strongly correlated with dissemination to regional lymph nodes (29). However, Kinoshita et al. (22) and Gunningham et al. (23) did not obtain a significant relationship between VEGF-C expression and lymph node metastasis. Notably, Gunningham et al. (23) used RT-PCR assay for their study. As seen in our present study, VEGF-C expression could also be observed in normal breast epithelium. Therefore, RT-PCR assay could not reveal tumor VEGF-C expression correctly if microdissection was not performed. The discrepancy between our findings and
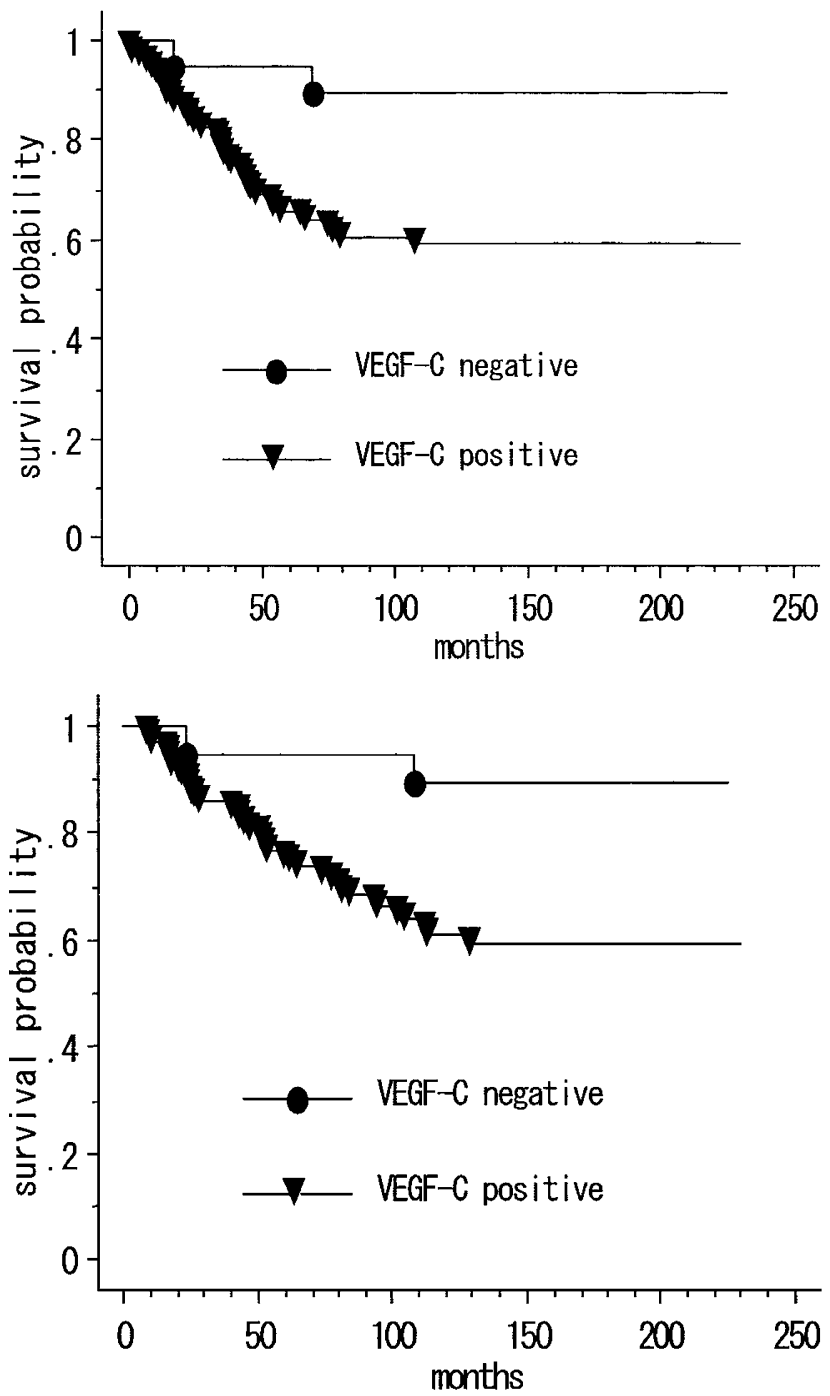

FIGURE 2. DFS (A) and OS (B) curves stratified according to vascula endothelial growth factor-C (VEGF-C) expression.

those reported by Kinoshita et al. (22) may be due to use of different antibodies.

It is very important for practical medical purposes to clarify whether VEGF-C expression will really prove to be a prognostic indicator for breast carcinoma. In our results, survival curves determined by the Kaplan-Meier method and univariate analysis demonstrated that VEGF-C expression was associated with both DFS and OS; however, we failed to identify VEGF-C expression as an independent prognostic factor for DFS and OS. Previous study shows that VEGF-C-induced lymphangiogenesis is strongly correlated with dissemination to regional lymph nodes in animal model (29). Based on these results, VEGF-C positivity is the predominant predictor of nodal positivity. The predictive value of VEGF-C for OS and DFS was dependent on lymph node metastasis. However, Kinoshita et al. (22) and Yang et al. (24) did not obtain a significant relationship between VEGF-C expression and prog- 
TABLE 3. Univariate Analysis of Overall Survival (OS) by Various Clinicopathological Factors

\begin{tabular}{|c|c|c|c|}
\hline \multirow{2}{*}{ Factor } & \multirow{2}{*}{ Number } & \multicolumn{2}{|l|}{ OS } \\
\hline & & Number of Deaths (\%) & P Value \\
\hline Age & & & 0.1414 \\
\hline$<50$ & 68 & $19(28.0)$ & \\
\hline$\geq 50$ & 55 & $21(38.2)$ & \\
\hline Histology & & & 0.1866 \\
\hline IDC & 114 & $39(34.2)$ & \\
\hline Others & 9 & $1(11.1)$ & \\
\hline Tumor size & & & 0.0327 \\
\hline$\leq 2 \mathrm{~cm}$ & 39 & $7(18.0)$ & \\
\hline$>2 \mathrm{~cm}$ & 79 & $29(36.3)$ & \\
\hline Lymph node metastasis & & & 0.0002 \\
\hline Negative & 59 & $11(18.7)$ & \\
\hline Positive & 64 & $29(45.3)$ & \\
\hline ER & & & 0.1997 \\
\hline Negative & 49 & $18(36.7)$ & \\
\hline Positive & 73 & $21(28.7)$ & \\
\hline PgR & & & 0.0313 \\
\hline Negative & 55 & $22(40.0)$ & \\
\hline Positive & 66 & $16(24.2)$ & \\
\hline c-erbB-2 & & & 0.1108 \\
\hline Negative & 87 & $25(28.7)$ & \\
\hline Positive & 36 & $15(41.6)$ & \\
\hline p53 & & & 0.6106 \\
\hline Negative & 79 & $27(34.1)$ & \\
\hline Positive & 43 & $12(27.9)$ & \\
\hline Grade & & & 0.8258 \\
\hline I and II & 69 & $24(34.7)$ & \\
\hline III & 54 & $16(29.7)$ & \\
\hline VEGF-C & & & 0.0175 \\
\hline Negative & 20 & $2(10.0)$ & \\
\hline Positive & 103 & 38 (36.8) & \\
\hline
\end{tabular}

nosis. The discrepancy between our findings and those reports may be due to use of different antibodies.

In conclusion, VEGF-C expression may play a crucial role in lymph node metastasis of breast cancers. Furthermore, VEGF-C expression serves as a significant prognostic factor for long-term survival in breast cancer. It is possible that VEGF-C will become a target for anti-angiogenic therapy for breast cancer.

\section{REFERENCES}

1. Senger DR, Van de Water L, Brown LF, Nagy JA, Yeo KT, Yeo TK, et al. Vascular permeability factor (VPF, VEGF) in tumor biology. Cancer Metastasis Rev 1993;12:303-24.

2. Korpelainen EI, Alitalo K. Signaling angiogenesis and lymphangiogenesis. Curr Opin Cell Biol 1998;10:159-64.

3. Beck LJ, D'Amore P. Vascular development: cellular and molecular regulation. FASEB J 1997;11:365-73.

4. Ellis L, Fidler I. Angiogenesis and metastasis. Eur J Cancer 1996;32A:2451-60.

5. Cao Y, Linden P, Farnebo J, Cao R, Eriksson A, Kumar V, et al. Vascular endothelial growth factor $\mathrm{C}$ induces angiogenesis in vivo. Proc Natl Acad Sci U S A 1998;95:14389-94.

6. Yonekura H, Sakurai S, Liu X, Migita H, Wang H, Yamagishi $\mathrm{S}$, et al. Placenta growth factor and vascular endothelial factor B and C expression in microvascular endothelial cells and pericytes. Implication in autocrine and paracrine regulation of angiogenesis. J Biol Chem 1999;274:35172-8.

7. Kaipainen A, Korhonen J, Mustonen T, van Hinsbergh VW, Fang GH, Dumont D, et al. Expression of the fms-like ty- rosine kinase 4 gene becomes restricted to lymphatic endothelium during development. Proc Natl Acad Sci U S A 1995;92:3566-70.

8. Partanen TA, Arola J, Saaristo A, Jussila L, Ora A, Miettinen $\mathrm{M}$, et al. VEGF-C and VEGF-D expression in neuroendocrine cells and their receptor, VEGFR-3, in fenestrated blood vessels in human tissues. FASEB J 2000;14:2087-6.

9. Bunone G, Vigneri P, Mariani L, Buto S, Collini P, Pilotti S, et al. Expression of angiogenesis stimulators and inhibitors in human thyroid tumors and correlation with clinicopathological features. Am J Pathol 1999;155:1967-76.

10. Yonemura Y, Endo Y, Fujita H, Fushida S, Ninomiya I, Bandou E, et al. Role of vascular endothelial growth factor C expression in the development of lymph node metastasis in gastric cancer. Clin Cancer Res 1999;5:1823-9.

11. Akagi K, Ikeda Y, Miyazaki M, Abe T, Kinoshita J, Maehara Y, et al. Vascular endothelial growth factor C (VEGF-C) expression in human colorectal cancer tissues. Br J Cancer 2000; 83:887-91.

12. Kitadai Y, Amioka T, Haruma K, Tanaka S, Yoshihara M, Sumii $\mathrm{K}$, et al. Clinicopathological significance of vascular endothelial growth factor (VEGF)-C in human squamous cell carcinomas. Int J Cancer 2001;93:662-6.

13. Gunningham SP, Currie MJ, Han C, Turner K, Scott PA, Robinson BA, et al. Vascular endothelial growth factor-B and vascular endothelial growth factor-C expression in renal cell carcinomas: regulation by the von Hippel-Lindau gene and hypoxia. Cancer Res 2001;61:3206-11.

14. O-charoenrat P, Rhys-Evans P, Modjtahedi H, Eccles SA. Vascular endothelial growth factor family members are differentially regulated by c-erbB signaling in head and neck squamous carcinoma cells. Clin Exp Metastasis 2000;18:15561.

15. Tsurusaki T, Kanda S, Sakai H, Kanetake H, Saito Y, Alitalo K, et al. Vascular endothelial growth factor-C expression in human prostatic carcinoma and its relationship to lymph node metastasis. Br J Cancer 1999;80:309-13.

16. Ueda M, Terai Y, Kumagai K, Ueki K, Yamaguchi H, Akise D, et al. Vascular endothelial growth factor $\mathrm{C}$ gene expression is closely related to invasion phenotype in gynecological tumor cells. Gynecol Oncol 2001;82:162-6.

17. Niki T, Iba S, Tokunou M, Yamada T, Matsuno Y, Hirohashi S. Expression of vascular endothelial growth factors A, B, C, and $\mathrm{D}$ and their relationship to lymph node status in lung adenocarcinoma. Clin Cancer Res 2000;6:2431-9.

18. Ohta Y, Shridhar V, Bright RK, Kalemkerian GP, Du W, Carbone $\mathrm{M}$, et al. VEGF and VEGF type C play an important role in angiogenesis and lymphangiogenesis in human malignant mesothelioma tumours. Br J Cancer 1999;81:54-61.

19. Korshunov A, Golanov A. The prognostic significance of vascular endothelial growth factor (VEGF C-1) immunoexpression in oligodendroglioma. An analysis of 91 cases. J Neurooncol 2000;48:13-9.

20. Veronesi U, Luini A, Galimberti V, Marchini S, Sacchini V, Rilke F. Extent of metastatic axillary involvement in 1446 cases of breast cancer. Eur J Surg Oncol 1990;16:127-33.

21. Skobe M, Hawighorst T, Jackson DG, Prevo R, Janes L, Velasco $\mathrm{P}$, et al. Induction of tumor lymphangiogenesis by VEGF-C promotes breast cancer metastasis. Nat Med 2001; 7:192-8.

22. Kinoshita J, Kitamura K, Kabashima A, Saeki H, Tanaka S, Sugimachi K. Clinical significance of vascular endothelial growth factor-C (VEGF-C) in breast cancer. Breast Cancer Res Treat 2001;66:159-64.

23. Gunningham SP, Currie MJ, Han C, Robinson BA, Scott PA, Harris AL, et al. The short form of the alternatively spliced flt- 4 but not its ligand vascular endothelial growth factor $\mathrm{C}$ is related to lymph node metastasis in human breast cancers. Clin Cancer Res 2000;6:4278-86. 
24. Yang W, Klos K, Yang Y, Smith TL, Shi D, Yu D. ErbB2 overexpression correlates with increased expression of vascular endothelial growth factors A, C, and D in human breast carcinoma. Cancer 2002;94:2855-61.

25. World Health Organization. Histological typing of breast tumors. 2nd ed. International histological classification of tumors. No. 2. Geneva, Switzerland: World Health Organization; 1981.

26. Tsuda H, Akiyama F, Kurosumi M, Sakamoto G, Watanabe T. Establishment of histological criteria for high-risk nodenegative breast carcinoma for a multi-institutional randomized clinical trial of adjuvant therapy. Japan National Surgical Adjuvant Study of Breast Cancer (NSAS-BC) Pathology Section 1998;28:486-91.

27. Fox SB, Gatter KC, Bicknell R, Going JJ, Stanton P, Cooke TG, et al. Relationship of endothelial cell proliferation to tumor vascularity in human cancer. Cancer Res 1993;53:4161-3.

28. Osborne CK, Hobbs K, Trent JM. Biological differences among MCF-7 human breast cancer cell lines from different laboratories. Breast Cancer Res Treat 1987;9:111-21.
29. Mattila MM, Ruohola JK, Karpanen T, Jackson DG, Alitalo K, Harkonen PL. VEGF-C induced lymphangiogenesis is associated with lymph node metastasis in orthotopic MCF-7 tumors. Int J Cancer 2002;98:946-51.

30. Hayes DF, Bast RC, Desch CE, Fritsche H Jr, Kemeny NE, Jessup JM, et al. Tumor marker utility grading system: a framework to evaluate clinical utility of tumor markers. J Natl Cancer Inst 1996;88:1456-66.

31. Goldhirsch A, Wood WC, Senn HJ, Glick JH, Gelber RD. International consensus panel on the treatment of primary breast cancer. Eur J Cancer 1995;31:1754-9.

32. Veronesi U, Marubini E, Del Vecchio M, Manzari A, Andreola $\mathrm{S}$, Greco M, et al. Local recurrences and distant metastases after conservative breast cancer treatments: partly independent events. J Natl Cancer Inst 1995;87:19-27.

33. Todd JH, Dowle C, Williams MR, Elston CW, Ellis IO, Hinton $\mathrm{CP}$, et al. Confirmation of a prognostic index in primary breast cancer. Br J Cancer 1987;56:489-92. 16

\section{Book Review}

Pai GS, Lewandowski RC Jr., Borgaonkar DS: Handbook of Chromosomal Syndromes, 376 pp, New York, Wiley-Liss, 2002 (\$99.95).

Every medical student knows that the Down syndrome is linked to trisomy of chromosome 21. Few of us do, however, realize that it took 93 years for this fact to become established-from 1866 when the Down syndrome was first described until 1959 when the trisomy 21 was discovered. Since then hundreds of cytogenetic abnormalities have been discovered, and chromosomal analysis has become a routine test in evaluating many childhood diseases.

In this book the authors present the most important chromosomal developmental syn- dromes. The disorders are listed by the affected chromosome number from 1 to 22 and the sex chromosomes. The clinical features of each syndrome are briefly outlined and illustrated with black and white photographs. The text is sketchy but to the point and informative. Key references also are included.

This book could be used for quick reference by neonatologists, genetic counselors, and general pediatricians. It also deserves to be included in hospital and departmental libraries.

\author{
Jadranka Popović \\ Children's Mercy Hospital \\ Kansas City, Missouri
}

